\title{
Improvement of cadmium tolerance and accumulation of Phragmites spp. Tabarka by ethyl methane sulfonate mutagenesis
}

\author{
Young-Nam Kim $\cdot$ Jiseong Kim $\cdot$ Jeongeun Lee $\cdot$ Sujung Kim $\cdot$ Keum-Ah Lee $\cdot$ Sun-Hyung Kim
}

Received: 18 December 2020 / Revised: 22 December 2020 / Accepted: 22 December 2020

(C) Korean Society for Plant Biotechnology

\begin{abstract}
Reed (Phragmites spp.) is a rhizomatous plant of the Poaceae family and is known as high tolerant plant to heavy metal contaminants. This plant is widely recognized as a $\mathrm{Cd}$ root-accumulator, but improved heavy metal tolerance and uptake capacity are still required for phytoremediation efficiency. To enhance capacity of hyperaccumulator plants, ethyl methane sulfonate (EMS) as chemical mutagen has been introduced and applied to remediation approaches. This study aimed to select EMS-mutagenized reeds representing high $\mathrm{Cd}$ resistance and large biomass and to investigate their ability of Cd accumulation. After 6 months cultivation of $\mathrm{M}_{2}$ mutant reeds under $\mathrm{Cd}$ stress conditions (up to $1,500 \mu \mathrm{M}$ ), we discovered seven mutant individuals that showed good performances like survivorship, vitality, and high accumulation of $\mathrm{Cd}$, particularly in their roots. Compared to wild type (WT) reeds as control, on average, dry weight of mutant type (MT) reeds was larger by 2 and 1.5 times in roots and shoots, respectively. In addition, these mutant plants accumulated 6 times more $\mathrm{Cd}$, mostly in the roots. In particular, MT8 reeds showed the greatest ability to accumulate $\mathrm{Cd}$. These results suggest that EMS mutagenesis could generate hyperaccumulator plants with enhanced $\mathrm{Cd}$ tolerance and biomass, thereby contributing to improvement of phytoremediation efficiency in Cd-contaminated soil or wastewater. Further studies should focus on identifying Cd tolerance mechanisms of such EMS-mutagenized plants, developing techniques for its biomass production, and investigating the practical potential of the EMS mutants for phytoremediation.
\end{abstract}

Keywords Ethyl methane sulfonate, Mutant reed, $\mathrm{Cd}$ tolerance, Hyperaccumulator, Phytoremediation

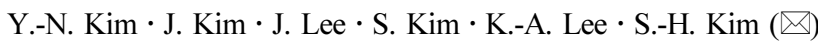
Department of Environmental Horticulture, University of Seoul, Seoul 02504, Republic of Korea

e-mail: pgel2006@gmail.com

\section{Introduction}

Today, rapid increase in industrial activity and urbanization have caused environmental issues albeit enriching human life. In particular, anthropogenic activities along with excessive use of toxic substances (e.g., heavy metals) have resulted in the loss of natural self-purification, causing serious environmental contamination (Hill 2010). Of the numerous contaminants known to date, heavy metals (HMs) such as $\mathrm{Cu}, \mathrm{Fe}, \mathrm{Zn}, \mathrm{Mn}$, and Mo are microelements for plants and essential for metabolism of living organisms up to a certain level (Ali et al. 2019). On the other hand, the rest of $\mathrm{HMs}$ such as $\mathrm{As}, \mathrm{Cd}, \mathrm{Cr}, \mathrm{Hg}, \mathrm{Ni}, \mathrm{Pb}$, and $\mathrm{Se}$ are regarded as toxic pollutants even at low level, detrimentally affecting flora, fauna, and human life. Such toxic metals have been released mainly from anthropogenically-disturbed areas (e.g., traffic, mining, smeltery etc.), consequently degrading soil function and ecosystem service.

Plant can be used to remediate soil contaminated with $\mathrm{HMs}$, which technology is called as phytoremediation. In the past decades, phytoremediation has been considered as one of the most environmentally-friendly and ecological techniques that remove, decompose, and stabilize environmental contaminants such as HMs, explosives, and organic pollutants. Additionally, this remediation method is costeffective, field-applicable, and non-invasive relative to other methods including excavation, thermal treatment, chemical extraction etc (Arthur et al. 2005; Cherian and Oliveira 2005).

Hyperaccumulator plants have been preferred for phytoremediation in soil contaminated with HMs. However, such plants mostly have a low capacity of biomass production (Kim et al. 2011a) that reduces efficiency for removal of HMs. To improve the phytoremediation efficiency, transgenic plants with enhanced tolerance to HMs have been recently introduced (e.g., Das et al. 2016; Kim et al. $2011 \mathrm{~b}$ etc.), but there are concerns about potential of ecological disturbance. As an alternative to transgenic 
technology, chemical mutagenesis has been often used to generate mutant plants with enhanced HMs tolerance and accumulation (Phang et al. 2012). Of chemical mutagens, ethyl methane sulfonate (EMS) is popular since it can cause low mortality and is highly mutagenic for creating a high proportion of phenotypic variation in mutant plants (Maple and Møller 2007; Phang et al. 2012). In previous studies, enhanced HMs tolerance and accumulation capacity and biomass production were found in the EMS-mutagenized Arabidopsis (Chen et al. 1997) and sunflower (Nehnevajova et al. 2012) plants, suggesting that mutagenesis treatments with EMS could be a successful means to generate mutants highly tolerant to the HMs stress.

Reed, Phragmites spp., is a perennial plant belonging to the family of Poaceae. This species is widely distributed in the temperate and subarctic zones colonizing mainly around wetlands, seashores, and lakes. Because of HMs uptake ability and tolerance, reed has been widely used for biomonitoring and purification in soil and water contaminated with HMs derived from industrial activities, domestic sewage, and agricultural sewage (Mantovi et al. 2003; Negri 1996; Poonawala et al. 1999). Hence, we expected generation of mutant reeds via EMS treatment to seeds would improve potential of the plants to remediate environments with HMs contaminants. This study aimed to identify Cd-resistant mutant reeds generated through EMS mutagenesis and investigate their capacity of $\mathrm{Cd}$ accumulation to serve as a candidate for phytoremediation.

\section{Materials and Methods}

Preparation for seeds

Mature seeds of Phragmites spp. Tabarka were harvested to use in the present study. Following cleaning and disinfection, the reed seeds were soaked in deionized (DI) water for 16 hours to sufficiently absorb moisture prior to induction of mutation.

\section{Chemical mutagenesis}

As a chemical mutagen, ethyl methane sulfonate was used in the present study and applied to seeds of Phragmites spp. Tabarka. The mutagenesis procedure is as follows (Fig. 1). Several hundreds of reed seeds sufficiently absorbed moisture for 16 hours were immersed in $0.5 \%$ and $1 \%$ EMS solutions, respectively, dissolved in $0.1 \mathrm{M} \mathrm{K-P}$ (potassium phosphate buffer, $\mathrm{pH}$ 7.0) and then inoculated in the dark

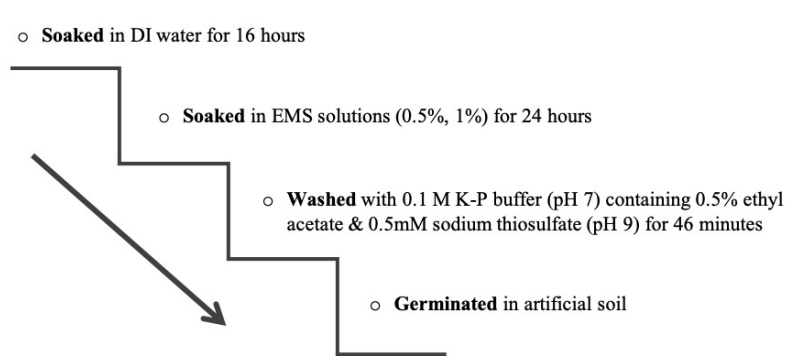

Fig. 1 Process of EMS (ethyl methane sulfonate) treatment on seeds of Phragmites spp. Tabarka

for 24 hours. Afterward, all seeds were washed using $0.1 \mathrm{M}$ K-P buffer ( $\mathrm{pH} 7.0$ ) containing $0.5 \%$ ethyl acetate, and then washed with $0.5 \mathrm{mM}$ sodium thiosulfate solution ( $\mathrm{pH} 9.0$ ) for 45 minutes. The EMS-treated seeds were acclimated and sown in artificial soil. The rate of seed germination treated with EMS ranged between $60 \%$ and $70 \%$ which is slightly lower than that of untreated seeds at $80 \%$. The mutant plants were self-fertilized and $\mathrm{M}_{2}$ cultivars were used in $\mathrm{Cd}$ resistance trial.

\section{Cd resistance test}

To identify mutant individuals with high $\mathrm{Cd}$ tolerance and large biomass, a total of 1,000 EMS-mutagenized $\mathrm{M}_{2}$ seeds selected based on growth vigor were transplanted into smallsized pots (10 cm diameter) containing artificial soil and grown in a glass house at the University of Seoul. For nutrient supply, about $20 \mathrm{~mL}$ of $1 / 2000$ diluted solution of Hyponex liquid fertilizer (N-P-K: 6-10-5) was applied monthly. For Cd resistance test, one-year-old seedling of mutant reeds were used. The seedlings of MT and WT planted in the pots were transferred to large plastic trays (see Fig. 2). For first three months, the plants were cultivated in water ponding condition added with $250 \mu \mathrm{M} \mathrm{Cd}$ solution. Among the seedlings, eleven mutants representing high resistance to $\mathrm{Cd}$ toxicity were selected, and continued to cultivate in higher concentration of $\mathrm{Cd}$ solution, up to $1500 \mu \mathrm{M}$, for next 3 months (Fig. 2).

Plant analysis

Following 6 months cultivation under Cd stress conditions, mortality of individual plants was checked and all plants were photographed to compare their growth. All plant samples were thoroughly washed with DI water and split as root and shoot parts. Following oven-drying at $70^{\circ} \mathrm{C}$ for 3 days, dry weight (DW) of the plant parts were measured. The concentrations of $\mathrm{Cd}$ in the plant parts were determined 


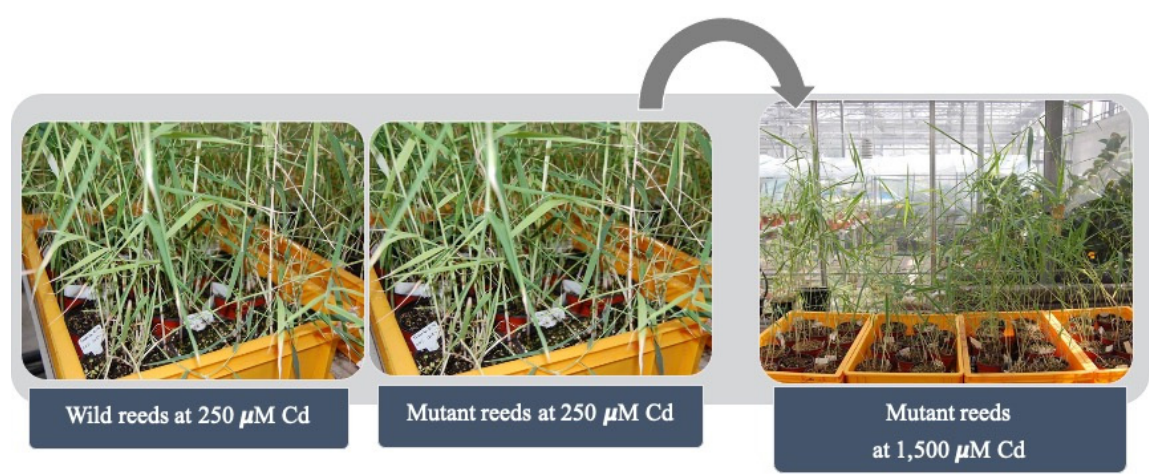

Fig. 2 Selection of seedlings of Phragmites spp. Tabarka representing Cd resistance at $250 \mu \mathrm{M}$ (left) and 1,500 $\mu \mathrm{M}$ (right). Reed seedlings of both wild and mutant types were grown at the low level of $\mathrm{Cd}$ for the first 3 months and subsequent at the higher level for the next 3 months

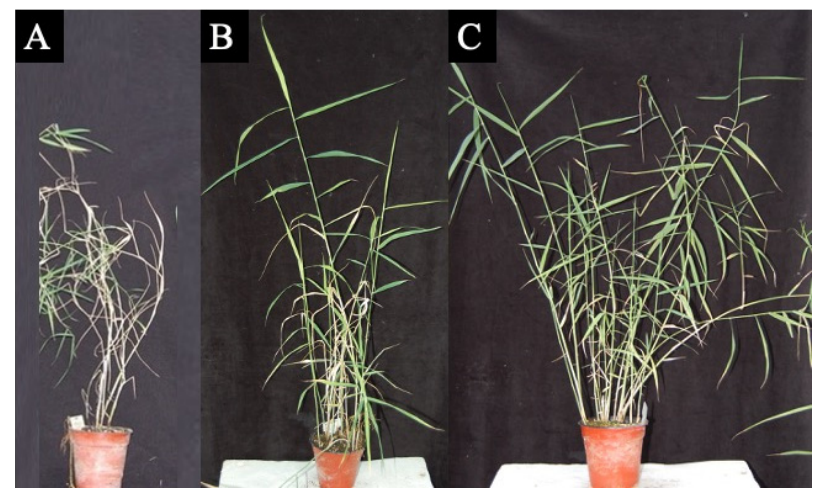

Fig. 3 Seedling growth of Phragmites exposed to Cd stress at up to $1,500 \mu \mathrm{M}$ during six months. A: wild type (WT2), B: mutant type (MT4) treated with $0.5 \%$ EMS, C: mutant type (MT8) treated with 1\% EMS

using an atomic absorption spectrophotometry (AAS-6800, Shimadzu, Japan) following digestion in a solution of concentrated $\mathrm{H}_{2} \mathrm{SO}_{4}$ and $60 \% \mathrm{HClO}_{4}(1: 10$, v:v) (Cresser and Parsons 1979). There were three replicates for determining the $\mathrm{Cd}$ concentration of each plant. The accumulation of $\mathrm{Cd}$ in plant parts and translocation factor (TF) of $\mathrm{Cd}$ from roots to shoots were evaluated as follows (Ullah et al. 2020):
$\mathrm{Cd}$ accumulation $=\mathrm{DW}$ (biomass $) \times \mathrm{Cd}$ concentration in plant parts

$\mathrm{TF}=\mathrm{Cd}$ concentration in shoots / Cd concentration in roots

\section{Results}

Mortality and growth of plants

During first 3 months, almost WT reed seedlings exposed at $250 \mu \mathrm{M} \mathrm{Cd}$ appeared to have morphological damages with blight or wilt symptoms, whilst some of EMS-muta- genized seedlings (11 individuals) representing high vigor (Fig. 2). Of the Cd tolerant mutant plants, seven individuals had good performance on their growth in response to the metal toxicity at 1,500 $\mu \mathrm{M}$ over the further 3 months (Fig. 3). On the other hand, the rest of MT and WT plants were mostly wilted. On average, MT reed seedlings had larger DW, about 2 times, than WT seedlings (Table 1). In particular, DW of MT4 (29.46 g) and MT8 (29.43 g) reeds, which had the best growth vigor under $\mathrm{Cd}$ stress condition, were about 3.6 times larger than that of WT reeds $(8.35 \mathrm{~g})$. Overall, the biomass among MT reeds considerably varied, indicating that each mutant individual could have different $\mathrm{Cd}$ resistance regardless of the EMS concentration treated.

\section{Cd concentration in plants}

Between WT and MT reeds, there is an opposite tendency for $\mathrm{Cd}$ concentrations in plant parts, such as roots and shoots (Fig. 4). On average, Cd concentration in roots of WT reeds $(13.0 \mathrm{mg} / \mathrm{kg})$ was doubly lower than that of MT reeds $(28.7 \mathrm{mg} / \mathrm{kg})$. On the other hand, higher concentration of Cd was found in shoots of WT reeds $(0.41 \mathrm{mg} / \mathrm{kg})$ mostly represented wilt damage (see Fig. 3). Among MT reeds, MT4 and MT8 with the best growth had the highest Cd concentrations in their roots: 79.7 and $87.1 \mathrm{mg} / \mathrm{kg}$, respectively. Especially, shoots of MT8 had the highest concentration of Cd $(0.89 \mathrm{mg} / \mathrm{kg})$, indicating that, of all EMS-mutagenized reeds, MT8 is most likely to transfer $\mathrm{Cd}$ ions from roots to shoot, resulting in $\mathrm{Cd}$ accumulation in the shoot part.

Accumulation and translocation of $\mathrm{Cd}$ in plants

On average, EMS-mutagenized reeds $(0.53 \mathrm{mg})$ absorbed and accumulated 5.9 times more $\mathrm{Cd}$ than WT reeds $(0.09$ $\mathrm{mg}$ ) (Table 2). Of the mutants, MT8 plant contained the 
Table 1 Dry weight and mortality of Phragmites seedlings treated with $0.5 \%$ and 1\% EMS following 6 months' cultivation under Cd stress

\begin{tabular}{|c|c|c|c|c|c|}
\hline \multirow{2}{*}{ Type } & \multirow{2}{*}{ ID } & \multirow{2}{*}{ EMS concentration } & \multicolumn{2}{|c|}{ Dry weight $(\mathrm{g})$} & \multirow{2}{*}{ Mortality } \\
\hline & & & Root & Shoot & \\
\hline \multirow{4}{*}{ Wild } & WT1 & - & 6.55 & 1.79 & $\mathrm{O}$ \\
\hline & WT2 & - & 6.90 & 2.53 & $\mathrm{O}$ \\
\hline & WT3 & - & 4.59 & 2.40 & $\mathrm{O}$ \\
\hline & \multicolumn{2}{|c|}{ Average } & 6.01 & 2.24 & \\
\hline \multirow{12}{*}{ Mutant } & MT1 & $0.5 \%$ & 1.97 & 2.37 & $\mathrm{O}$ \\
\hline & MT2 & $0.5 \%$ & 5.56 & 2.62 & $\mathrm{O}$ \\
\hline & MT3 & $0.5 \%$ & 2.85 & 2.79 & $\mathrm{X}$ \\
\hline & MT4 & $0.5 \%$ & 24.29 & 5.14 & $\mathrm{X}$ \\
\hline & MT5 & $0.5 \%$ & 20.37 & 4.02 & $\mathrm{X}$ \\
\hline & MT6 & $1 \%$ & 5.30 & 1.21 & $\mathrm{O}$ \\
\hline & MT7 & $1 \%$ & 22.91 & 3.72 & $\mathrm{O}$ \\
\hline & MT8 & $1 \%$ & 25.63 & 3.83 & $\mathrm{X}$ \\
\hline & MT9 & $1 \%$ & 3.73 & 2.15 & $\mathrm{X}$ \\
\hline & MT10 & $1 \%$ & 14.04 & 5.25 & $\mathrm{X}$ \\
\hline & MT11 & $1 \%$ & 10.24 & 3.66 & $X$ \\
\hline & \multicolumn{2}{|c|}{ Average } & 12.44 & 3.34 & \\
\hline
\end{tabular}

Table 2 Accumulation and translocation factor (TF) of Cd from roots to shoots in reed plants of wild and mutant types after 6 months' cultivation under $\mathrm{Cd}$ stress condition

\begin{tabular}{|c|c|c|c|c|c|}
\hline \multirow{2}{*}{ Type } & \multirow{2}{*}{ ID } & \multirow{2}{*}{ EMS concentration } & \multicolumn{2}{|c|}{ Cd content $(\mathrm{mg})$} & \multirow{2}{*}{$\mathrm{TF}$} \\
\hline & & & Root & Shoot & \\
\hline \multirow{4}{*}{ Wild } & WT1 & - & 0.08 & 0.001 & 0.04 \\
\hline & WT2 & - & 0.12 & 0.001 & 0.02 \\
\hline & WT3 & - & 0.06 & 0.003 & 0.03 \\
\hline & \multicolumn{2}{|c|}{ Average } & 0.09 & 0.002 & 0.03 \\
\hline \multirow{12}{*}{ Mutant } & MT1 & $0.5 \%$ & 0.02 & 0.002 & 0.08 \\
\hline & MT2 & $0.5 \%$ & 0.08 & 0.001 & 0.02 \\
\hline & MT3 & $0.5 \%$ & 0.01 & 0.001 & 0.12 \\
\hline & MT4 & $0.5 \%$ & 1.94 & 0.002 & 0.01 \\
\hline & MT5 & $0.5 \%$ & 0.46 & 0.002 & 0.01 \\
\hline & MT6 & $1 \%$ & 0.05 & $<0.001$ & 0.01 \\
\hline & MT7 & $1 \%$ & 0.97 & 0.001 & $<0.01$ \\
\hline & MT8 & $1 \%$ & 2.23 & 0.003 & 0.01 \\
\hline & MT9 & $1 \%$ & 0.04 & $<0.001$ & 0.01 \\
\hline & MT10 & $1 \%$ & 0.34 & 0.002 & 0.02 \\
\hline & MT11 & $1 \%$ & 0.13 & 0.001 & 0.01 \\
\hline & \multicolumn{2}{|c|}{ Average } & 0.57 & 0.001 & $\mathbf{0 . 0 3}$ \\
\hline
\end{tabular}

largest content of $\mathrm{Cd}(2.24 \mathrm{mg})$ in both roots and shoots, followed by MT4, MT7, MT10, and MT11 plants. As a result of translocation factor of $\mathrm{Cd}$ from roots to shoot, most of MT plants especially showing good vigor under $\mathrm{Cd}$ stress condition had very low TF values which accounts for less than 0.03 (Table 2). This appears that the ability of $\mathrm{Cd}$ translocation remained unchanged with or without EMS mutagenesis although there were differences in survival and biomass production under $\mathrm{Cd}$ stress condition.

\section{Discussion}

Cadmium is not a nutrient necessary for plant growth, but plants absorb it through roots. Normally, the absorbed $\mathrm{Cd}$ ions are retained mainly in the plant roots, but only small amounts can be transported to the stems or leaves (Toppi and Gabbrielli 1999), affecting plant growth and survival. In a general way, the $\mathrm{Cd}$ toxicity inhibits plant growth by causing various obstacles such as chlorosis, necrosis, water 

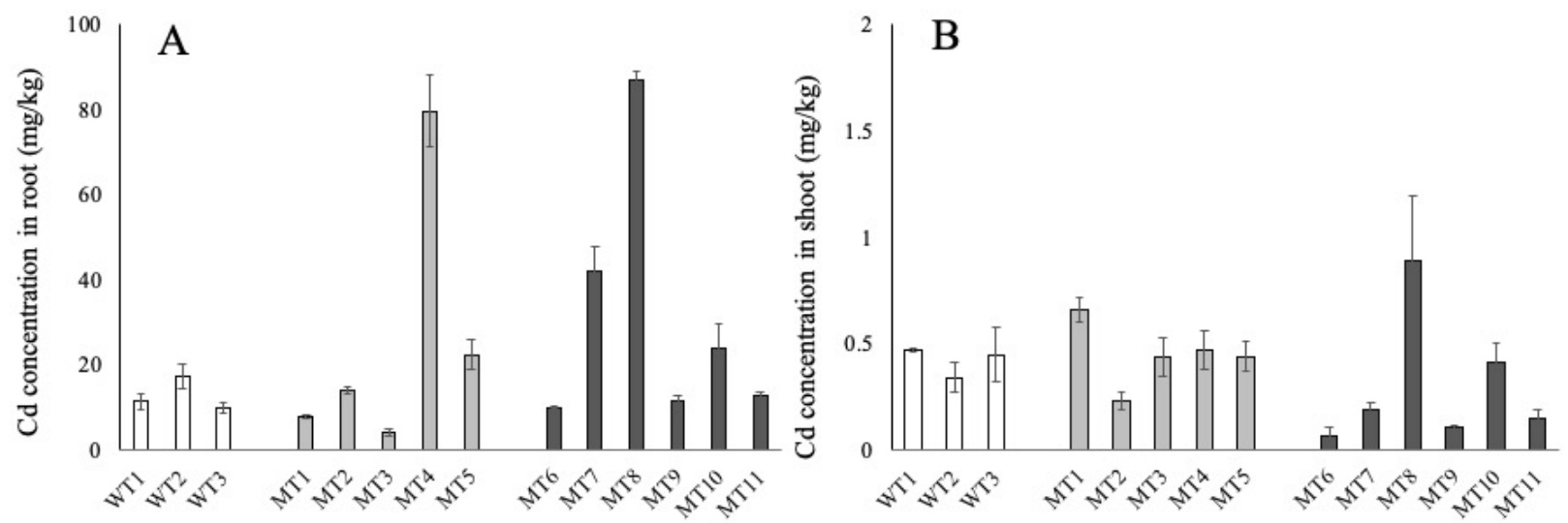

Fig. $4 \mathrm{Cd}$ concentration in root and shoot of Phragmites seedlings. Data indicate mean \pm standard errors ( $\mathrm{n}=3$ ). Wild types $(\square)$, Mutant types treated with $0.5 \%$ EMS $(\square)$, Mutant types treated with $1 \%$ EMS ( $\square$ ).

imbalance, phosphorus and nitrogen deficiency, accelerated senility, and withering (Benavides 2005; Das et al. 1997). Likewise, we observed that most of WT reed seedlings used in this study occurred such damage phenomenon like necrosis and spots on the leaves at $250 \mu \mathrm{M} \mathrm{Cd}$ treatment and were eventually died at 1,500 $\mu \mathrm{M} \mathrm{Cd}$ treatment (Fig. 3). On the other hand, a few of EMS-mutagenized $\mathrm{M}_{2}$ plants did overcome the Cd stress, although they had initial Cdrelated damages over the cultivation period. Through this study, of a thousand of the mutant reed plants, a total of 7 individuals were screened based on their vigorous growth with good morphology at $1,500 \mu \mathrm{M}$ Cd treatment (Fig. 2 and Fig. 3). This interesting finding of novel mutant plants with strong tolerance to $\mathrm{Cd}$ can be seen as having an important meaning in terms of researches on remediation for contaminants.

In general, reed (Phragmites spp.) is widely known as highly tolerant plant to a variety of environmental stresses such as heavy metals (Higuchi et al. 2015). In particular, this plant species accumulates $\mathrm{Cd}$ dominantly in roots rather than shoots (Ali et al. 2004; Stoltz and Greger 2002). Because of its high ability to accumulate $\mathrm{Cd}$ in the belowground plant parts, it has been widely recognized as a root hyperaccumulator for $\mathrm{Cd}$ (Ederli et al. 2004). As such, Phragmites can be a proper candidate for rhizofiltration in HMs contaminated soil or wastewater. Similar to the previous studies, our results showed that both WT and MT seedlings contained much more $\mathrm{Cd}$ in their roots than in shoots (Table 2). Also, both reed plants had very low TF values ranging from 0.01 up to 0.12 , indicating that the capacity of $\mathrm{Cd}$ translocation of reed plants was not changed by EMS mutagenesis. However, with considerable increase in biomass of both roots and shoots, MT4 and MT8 reeds showed improved ability of absorb and accumulate $\mathrm{Cd}$ in the plant parts.
To improve phytoremediation efficiency, hyperaccumulator plants with a large biomass and high tolerance to toxic substances including $\mathrm{Cd}$ have been explored around the world. However, despite a variety of plant species have been tested as candidates for phytoremediation, it is still hard to find proper plants satisfying at the restoration fields, to date. Recently, there have been big efforts to develop transgenic plants for purification of contaminants; however, this raises concerns about field applications due to potential ecological risks (Gunarathne et al. 2019). Considering not only the environmental issues but also the remediation efficiency, mutagenesis techniques would be a critical method to generate valuable plants for successful phytoremediation. In particular, the mutagenesis can produce mutants with heritable variations in the genomes, phenotypes and physiological responses, which is vital to maintain the intrinsic traits of the plants produced (Phang et al. 2012). Through this study, we found that EMS-mutagenized plants, particularly such as MT4 and MT8 isolated in this study, could have a significant potential to play a role as root hyperaccumulators in the contaminated soil or wastewater with $\mathrm{Cd}$. In order to enhance phytoremediation efficiency, therefore, further studies should focus on identifying Cd tolerance mechanisms of such EMS-mutagenized plants, developing technique for its biomass production, and investigating the practical potential of the EMS mutants for phytoremediation on a field situation.

\section{Conflict of interest}

The authors have no conflict of interest to declare. 


\section{References}

Ali H, Khan E, Ilahi I (2019) Environmental chemistry and ecotoxicology of hazardous heavy metals: environmental persistence, toxicity, and bioaccumulation. J Chem 2019: ID6730305

Ali NA, Bernal MP, Ater M(2004) Tolerance and bioaccumulation of cadmium by Phragmites australis grown in the presence of elevated concentrations of cadmium, copper, and zinc. Aquat Bot 80:163-176

Arthur EL, Rice PJ, Rice PJ, Anderson TA, Baladi SM (2005) Phytoremediation-an overview. Crit Rev Plant Sci 24:109-122

Benavides MP, Gallego SM, Tomaro ML (2005) Cadmium toxicity in plants. Braz J Plant Physiol 17(1):21-34

Chen J, Huang JW, Caspar T, Cunningham SD (1997) Arabidopsis thaliana as a model system for studying lead accumulation and tolerance in plants. In EL Kruger, TA Anderson, JR Coats, eds, Phytoremediation of soil and water contaminants. American Chemical Society, Washington. p 264

Cherian S, Oliveira MM (2005) Transgenic Plants in Phytoremediation: Recent Advance ad New Possibilities. Environ Sci Technol 39(24):9377-9390

Cresser MS, Parsons JW (1979) Sulfuric-perchloric acid digestion of plant material for the determination of nitrogen, phosphorus, potassium, calcium and magnesium. Anal Chem Acta 109: 431-436

Das N, Bhattacharya S, Maiti MK (2016) Enhanced cadmium accumulation and tolerance in transgenic tobacco overexpressing rice metal tolerance protein gene OsMTP1 is promising for phytoremediation. Plant Physiol Biochem 105:297-309

Das P, Samantaray S, Rout GR (1997) Studies on cadmium toxicity in plants: a review. Environ Pollut 98:29-36

Ederli L, Reale L, Ferranti F, Pasqualini S (2004) Response induced by high concentration of cadmium in Phragmites australis roots. Physiol Plant 121:66-74

Gunarathne V, Mayakaduwa S, Ashiq A, Weerakoon SR, Biswas JK, Vithanage M(2019) Transgenic plants: benefits, applications, and potential risks in phytoremediation. Transgenic Plant Technology for Remediation of Toxic Metals and Metalloids. Elsevier, U.K. pp 89-102

Hill MK (2010) Understanding environmental pollution. Cambridge University Press, Cambridge
Higuchi K, Kanai M, Tsuchiya M, Ishii H, Shibuya N, Fujita N, Nakamura Y, Suzui N, Fujimaki S, Miwa E (2015) Common reed accumulates starch in its stem by metabolic adaptation under Cd stress conditions. Front Plant Sci 6:138

Kim KH, Kim YN, Lim GH, Lee MN, Jung YH(2011a) Expression of catalase (CAT) and ascorbate peroxidase (APX) in MuS1 transgenic tobacco under cadmium stress. Korean J Soil Fert 44(1):53-57

Kim YN, Kim JS, Seo SG, Lee Y, Baek SW, Kim IS, Yoon HS, Kim KR, Kim SH, Kim KH (2011) Cadmium resistance in tobacco plants expressing the MuSI gene. Plant Biotechnol Rep 5:323-329

Maple J, Møller SG (2007) Mutagenesis in Arabidopsis. In E Rosato, ed, Circadian Rhythms. Humana Press. pp 197-206

Mantovi P, Marmiroli M, Maestri E, Tagliavini S, Piccinini S, Marmiroli N (2003) Application of a horizontal subsurface flow constructed wetland on treatment of dairy parlor wastewater. Bioresource Technol 88:85-94

Negri MC (1996) Plants that remove contaminants from the environment. Lab Med 27:36-9

Nehnevajova E, Lyubenova L, Herzig R, Schröder P, Schwitzguébel JP, Schmülling T (2012) Metal accumulation and response of antioxidant enzymes in seedlings and adult sunflower mutants with improved metal removal traits on a metal-contaminated soil. Environ Exp Botany 76:39-48

Phang IC, Taylor HH, Leung DWM (2012) Chemical mutagenesis for improving potential of plants to remediate environments with heavy metal contaminants. Curr Top Med Chem 11: 47-52

Poonawala IS, Jana MM, Nadgauda NS (1999) Factors influencing bud break and mass-scale micropropagation of three Phragmites species: P. karka, P. communis, and P. australis. Plant Cell Rep18:696-700

Stoltz E, Greger M (2002) Accumulation properties of As, Cd, Cu, $\mathrm{Pb}$ and $\mathrm{Zn}$ by four wetland plant species growing on submerged mine tailings. Environ Exp Bot 47:271-280

Toppi LS, Gabbrielli R (1999) Response to cadmium in higher plants. Environ Exp Bot 41(2):105-130

Ullah S, Khan J, Hayat K., Abdelfattah Elateeq A, Salam U, Yu B, Ma Y, Wang H, Tang ZH (2020) Comparative study of growth, cadmium accumulation and tolerance of three chickpea (Cicer arietinum L.) cultivars. Plants 9(3):310 